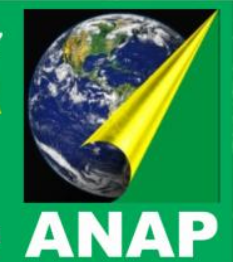

\title{
ANÁLISE DO FATURAMENTO DE CONSUMO DE ENERGIA ELÉTRICA PARA UMA USINA DE AÇÚCAR E ÁLCOOL NA REGIÃO DE QUATÁ
}

\author{
Valessa Orácio Rocha ${ }^{1}$ \\ Camila Pires Cremasco Gabriel ${ }^{2}$ \\ Luís Roberto Almeida Gabriel Filho \\ Daniel dos Santos Viais Neto ${ }^{4}$ \\ Eliane Regina Francisco da Silva ${ }^{5}$
}

RESUMO: O presente trabalho demonstra por meio da estatística descritiva a situação de faturamento de energia elétrica de uma usina de açúcar e álcool da região de Quatá. Com o intuito de avaliar a utilização da energia elétrica da usina, foram descritos os fatores que interferem no uso da energia elétrica, dados pelo fator de carga (fc) e fator de potência (fp). Nesse trabalho optamos pela estatística descritiva, cujo objetivo básico é o de sintetizar uma série de valores de mesma natureza, permitindo dessa forma que se tenha uma visão global da variação desses valores, organizando e descrevendo os dados de três maneiras: por meio de tabelas, de gráficos e de medidas descritivas. Foi elaborada uma planilha com a média de todos os meses dos anos de 2008 a 2010 a partir dos dados fornecidos pela concessionária de energia elétrica. Foi verificado que a empresa é extremamente eficiente, fato verificado durante estes três anos pela avaliação do fator de potência que geralmente foi 1,0. A empresa foi em média considerada racional, pois seu fator de carga calculado foi avaliado como regular nestes 3 anos.

\footnotetext{
1 Tecnólogo em Agronegócio. lessa_oracio@hotmail.com

${ }^{2}$ Licenciada em Matemática (FCT/UNESP), Mestre em Matemática Pura (DM/UFSCar), Doutora em Agronomia/Energia na Agricultura (FCA/UNESP) e Pós-doutoranda em Bioestatística (IB/UNESP), Professora Assistente da FATEC -

Presidente Prudente. camila@fatecpp.edu.br.

${ }^{3}$ Licenciado em Matemática (FCT/UNESP), Mestre em Matemática Pura (ICMC/USP), Doutor em Agronomia/Energia na Agricultura (FCA/UNESP) e Pós-doutorando em Agronomia/Energia na Agricultura (FCA/UNESP), Professor Assistente Doutor da CET/UNESP - Tupã/SP. gabrielfilho@tupa.unesp.br.

${ }^{4}$ Licenciado e Bacharel em Matemática (ICMC/USP), Mestre em Matemática Pura (ICMC/USP) e Doutorando em Agronomia/Irrigação e Drenagem (FCA/UNESP), Professor Associado da FATEC - Presidente Prudente. dvneto@fatecpp.edu.br.

5 Tecnólogo em Agronegócio pela Faculdade de Tecnologia de Presidente Prudente. lianeremendes@hotmail.com
} 
Palavras-chave: fator carga $(f c)$, fator de potência ( $f p)$,estatística descritiva

\section{INTRODUÇÃO}

De acordo com a Coordenadoria de Planejamento e Avaliação (CPA) e a Unidade de Assessoria Econômica (UAE) na região de Presidente Prudente a principal atividade econômica do município de Presidente Prudente é a agropecuária, tendo a produção de leite uma produção que ultrapassa um milhão de litros/ano.

A cidade possui mais de 400 indústrias, com produção voltada para alimentos, bebidas, laticínios, açúcar, borracha, curtumes, derivados de couro, vestuário, calçados, metalúrgicos, gráficos, químicos, farmacêuticos, entre outros.

Dentre os elos da cadeia leiteira são utilizadas grandes quantidades de produtos veterinários, material genético, alimentação animal, equipamentos para ordenha, sementes, fertilizantes e produtos químicos, além de embalagens, açúcar, equipamentos, indústrias e inclusive energia elétrica, o que contribuí para o giro da economia do país, como evidenciam Cônsoli e Neves (2006 apud Silva F.).

O índice fator de potência mostra o quanto da energia elétrica está sendo transformada em outras formas de energia necessárias para o funcionamento de determinados equipamentos. Quando o fator de potência é baixo, podem surgir problemas na instalação elétrica do consumidor e na rede de distribuição da concessionária. Podendo acarretar em conseqüências financeiras para o consumidor além de desperdício de energia acarretando em danos ambientais.

Com o intuito de avaliar a utilização da energia elétrica de uma usina, foram descritos os fatores que interferem no uso da energia elétrica, dados pelos fatores de carga e potência. Foram levadas em consideração as várias modalidades tarifárias, os grupos de unidades consumidoras e as condições básicas para o fornecimento de energia elétrica.

\section{OBJETIVO}




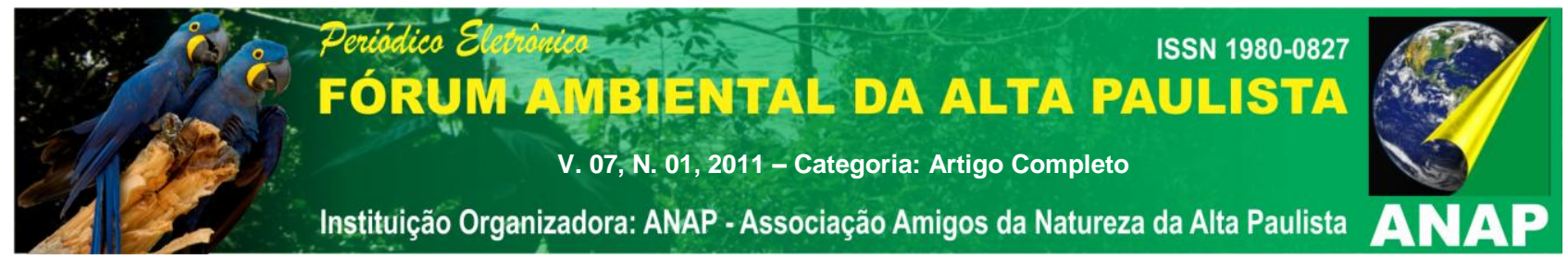

O presente trabalho tem por objetivo demonstrar estatística e descritivamente a situação de faturamento de energia elétrica de uma usina de açúcar e álcool da região de Quatá.

\section{METODOLOGIA}

Por meio de dados de faturamento de energia elétrica de uma usina de açúcar e álcool da região de Quatá foi avaliada a racionalidade e eficiência da utilização de energia elétrica, que tem como atividade a produção de açúcar e álcool. Os dados foram obtidos por meio de entrevistas com o responsável pela administração financeira, coletando os dados nas contas de energia de cada mês.

Foram coletados os dados de faturamento de energia de 3 anos, para análise da racionalidade e eficiência da utilização de energia elétrica.

As características teóricas de avaliação energética foram baseadas no modelo elaborado por Cremasco (2008). Dessa forma foi feita uma avaliação da forma de utilização de energia, da empresa estudada. Foi realizada uma entrevista com um especialista da concessionária de energia elétrica do sistema interligado REDE. E por fim foi realizada uma apresentação do modelo visando à racionalização de energia elétrica para a empresa.

As fórmulas do faturamento de energia elétrica foram consideradas de acordo com a revisão bibliográfica.

O procedimento descrito na revisão bibliográfica deste trabalho sobre faturamento da energia elétrica foi aplicado a cada 15 minutos nos dados de medição e assim calculado o faturamento total mensal somando-se cada parcela obtida nestas medições. O fator de potência e o fator de carga são obtidos fazendo-se médias aritméticas também de cada intervalo de medição de 15 minutos.

O fator de potência mensal é fornecido diretamente no relatório descritivo fornecido pela empresa de eletricidade. O fator de carga mensal foi calculado através da fórmula: 


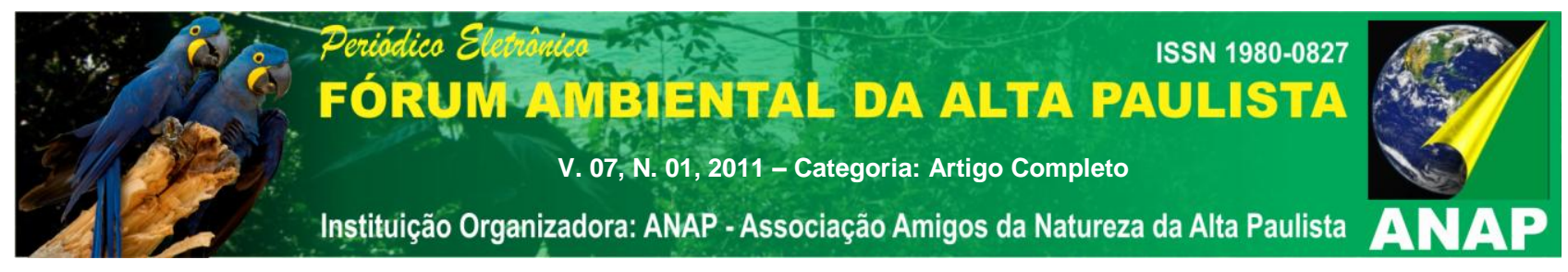

$$
f c=\frac{\text { Energia Ativa }}{\text { tempo } \times \text { Demanda }}
$$

As tarifas horo-sazonais utilizadas nas fórmulas do faturamento serão obtidas por médias ponderadas da seguinte forma:

$$
T=\frac{7 \cdot T_{s}+5 \cdot T_{u}}{12}
$$

Onde:

T é a tarifa utilizada nas fórmulas do faturamento, Ts é a tarifa no período seco (7 meses) e Tu é a tarifa no período úmido (5 meses)

A partir de dados de energia elétrica da empresa considerada, obteremos assim o fator de potência e o fator de carga mensal relativamente a todos os meses do período em estudo. O consumo médio será definido como a média aritmética dos meses do período em estudo.

\section{RESULTADOS E DISCUSSÃo}

Foram coletados dados de faturamento de energia elétrica de uma usina de açúcar e álcool da região de Quatá, dados mensais dos períodos de 2008, 2009 e 2010. A usina é atendida pelo grupo de tensão A e tipo de tarifa horossazonal verde.

$\mathrm{Na}$ Tabela 1, podemos avaliar o faturamento de energia elétrica dos doze meses do ano de 2008. 


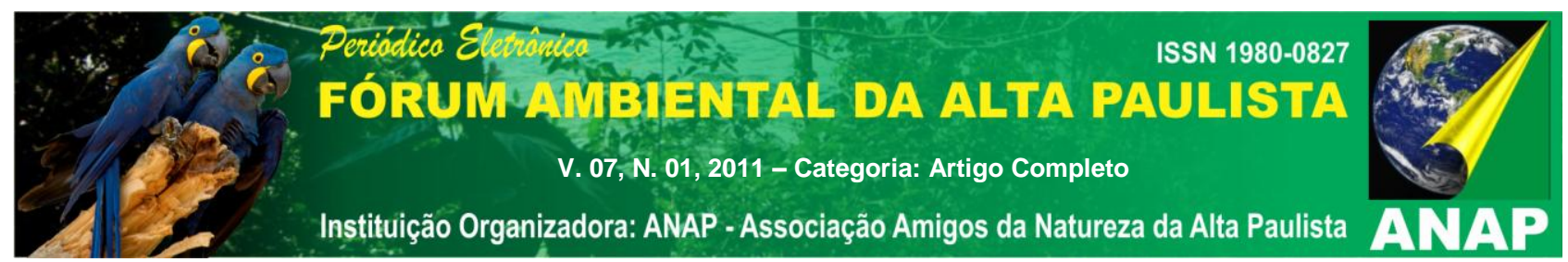

Tabela 1: Faturamento de energia elétrica no ano de 2008

\begin{tabular}{cccc}
\hline Referência & Quantidade Faturada & Quantidade Contratada & Fator de Potência \\
\hline jan-08 & 298.576 & 9.000 & 1,00 \\
fev-08 & 48.463 & 6.000 & 1,00 \\
mar-08 & 591.775 & 6.000 & 1,00 \\
abr-08 & 551.532 & 8.000 & 0,98 \\
mai-08 & 716.561 & 8.000 & 0,99 \\
jun-08 & 513.479 & 8.000 & 0,98 \\
jul-08 & 786.534 & 8.000 & 0,98 \\
ago-08 & 551.427 & 8.000 & 0,98 \\
set-08 & 561.834 & 8.000 & 0,97 \\
out-08 & 624.325 & 8.000 & 0,97 \\
nov-08 & 622.984 & 8.000 & 0,97 \\
dez-08 & 580.955 & 8.000 & 0,97 \\
\hline MÉDIA & 537.370 & 7.750 & 0,98 \\
\hline
\end{tabular}

Ao analisar os dados de faturamento de energia elétrica do ano de 2009, podemos observar na Tabela 2, que o fator de potência tem seu melhor desempenho a partir do início do período seco mês de maio.

Tabela 2: Faturamento de energia elétrica no ano de 2009

\begin{tabular}{rccc}
\hline Referência & Quantidade Faturada & Quantidade Contratada & Fator de Potência \\
\hline jan-09 & 834.614 & 7.111 & 0,98 \\
fev-09 & 652.457 & 8.058 & 0,96 \\
mar-09 & 1.116 .780 & 8.000 & 0,97 \\
abr-09 & 675.975 & 14.000 & 0,96 \\
mai-09 & 218.312 & 8.250 & 1,00 \\
jun-09 & 128.184 & 4.000 & 1,00 \\
jul-09 & 134.757 & 8.111 & 1,00 \\
ago-09 & 142.528 & 8.000 & 1,00 \\
set-09 & 215.820 & 8.200 & 1,00 \\
out-09 & 49.917 & 8.000 & 1,00 \\
nov-09 & 37.374 & 8.000 & 1,00 \\
dez-09 & 52.642 & 8.000 & 1,00 \\
\hline MÉDIA & 354.947 & 8.144 & 0,99 \\
\hline
\end{tabular}

A Tabela 3, com dados de 2010 mostra a melhor média de fator de potência, tendo constante eficiência durante todos os meses do ano. 


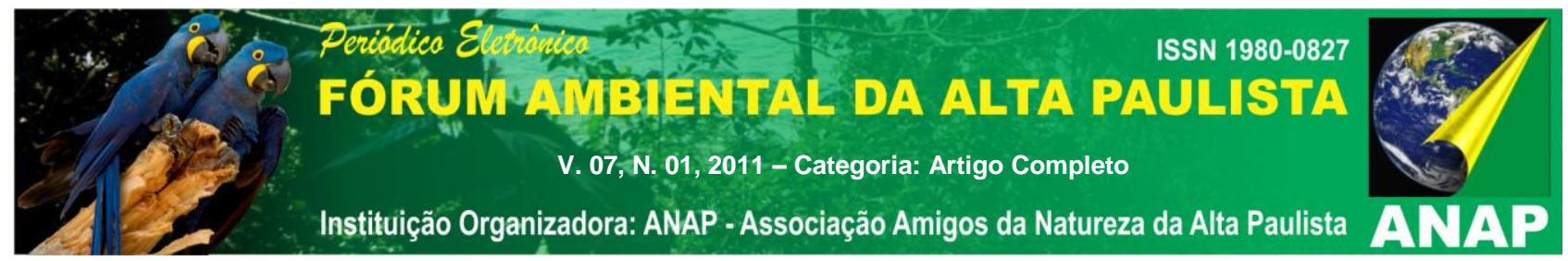

Tabela 3: Faturamento de energia elétrica no ano de 2010

\begin{tabular}{cccc}
\hline Referência & Quantidade Faturada & Quantidade Contratada & Fator de Potência \\
\hline jan-10 & 469.521 & 4.235 & 1,00 \\
fev-10 & 1.178 .455 & 9.000 & 1,00 \\
mar-10 & 231.197 & 9.000 & 1,00 \\
abr-10 & 32.835 & 9.000 & 1,00 \\
mai-10 & 12.304 & 9.000 & 1,00 \\
jun-10 & 21.697 & 9.000 & 1,00 \\
jul-10 & 83.566 & 9.000 & 1,00 \\
ago-10 & 21.357 & 9.000 & 1,00 \\
set-10 & 42.741 & 9.000 & 1,00 \\
out-10 & 26.707 & 9.000 & 1,00 \\
nov-10 & 63.789 & 9.000 & 1,00 \\
dez-10 & 186.481 & 9.000 & 1,00 \\
\hline MÉDIA & $\mathbf{1 9 7 . 5 5 4}$ & $\mathbf{8 . 6 0 2}$ & $\mathbf{1 , 0 0}$ \\
\hline
\end{tabular}

$\mathrm{Na}$ Tabela 4, podemos comparar que a quantidade faturada é o dado de maior variação nos períodos tendo como maior média o ano de 2008. Já as médias de quantidade contratada e fator de potência não tiveram muita variação.

Tabela 4: Média de faturamento de energia elétrica dos 3 anos

\begin{tabular}{cccc}
\hline Referência & Quantidade Faturada & Quantidade Contratada & Fator De Potência \\
\hline Média 2008 & 537.370 & 7.750 & 0,98 \\
Média 2009 & 119.357 & 8.835 & 0,99 \\
Média 2010 & 130.062 & 8.818 & 0,99 \\
\hline Média Total & 262.263 & 8.468 & 0,99 \\
\hline
\end{tabular}

\section{CONCLUSÃO}

Neste trabalho encontramos dificuldades na coleta de dados, os dados foram obtidos pela concessionária de energia elétrica Grupo Rede. Foi elaborada uma planilha com a média de todos os meses dos anos de 2008 a 2010 a partir dos dados fornecidos 


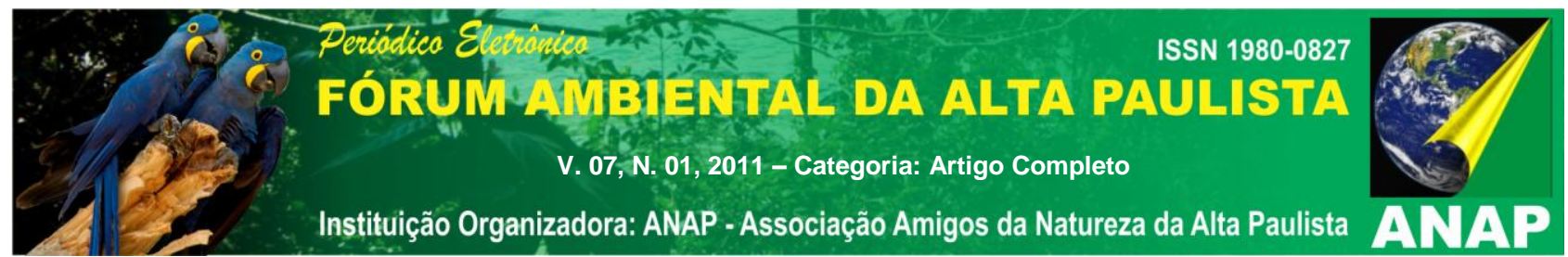

pela concessionária de energia elétrica. Verificamos que mesmo a empresa sendo uma Usina de açúcar e álcool, setor praticamente auto-suficiente, pois produzem sua própria energia, a quantidade faturada de energia foi elevada nos meses de maio e julho de 2008 (período seco).

Foi verificado que a empresa é extremamente eficiente, fato verificado durante estes três anos pela avaliação do fator de potência que geralmente foi 1,0. A empresa foi em média considerada racional, pois seu fator de carga calculado foi avaliado como regular nestes 3 anos.

Sugere-se que no período seco a empresa trabalhe com mais energia produzida por ela e poupe a energia contratada.

Em trabalhos futuros os dados pesquisados e analisados por meio de estatística descritiva apresentados nesta monografia poderão ser utilizados para criar um controlador para auxiliar quantitativamente a empresa durante o período seco.

\section{REFERÊNCIAS BIBLIOGRÁFICAS}

Atlas de Energia Elétrica do Brasil. Fatores de Conversão. Disponível em: < http://www.aneel.gov.br/arquivos/PDF/atlas_fatoresdeconversao_indice.pdf>. Acesso em: 18 out. 2010.

Balanço Energético Nacional 2010. Disponível em: <https://ben.epe.gov.br/downloads/Relatorio_Final_BEN_2010.pdf>. Acesso em: 19 out. 2010.

BUSSAD, Wilton. Inferência Estatística. Estatística Básica. São Paulo: Saraiva, 2002. p.1;255-271.

BRASIL. Agência Nacional de Energia Elétrica - ANEEL. Resolução Normativa № 414, de 2010. Estabelece as Condições Gerais de Fornecimento de Energia de forma atualizada e consolidada, set. 2010 .

BRASIL. Agência Nacional de Energia Elétrica - ANEEL. Resolução Normativa № 456, de 2010. Estabelece as Condições Gerais de Fornecimento de Energia, nov. 2000.

CREMASCO, Camila. Aplicação da lógica fuzzy para avaliação do faturamento do consumo de energia elétrica e demanda de uma empresa de avaliação de postura. 108 f. Tese apresentada para obtenção do título de Doutor em Agronomia - Área de 


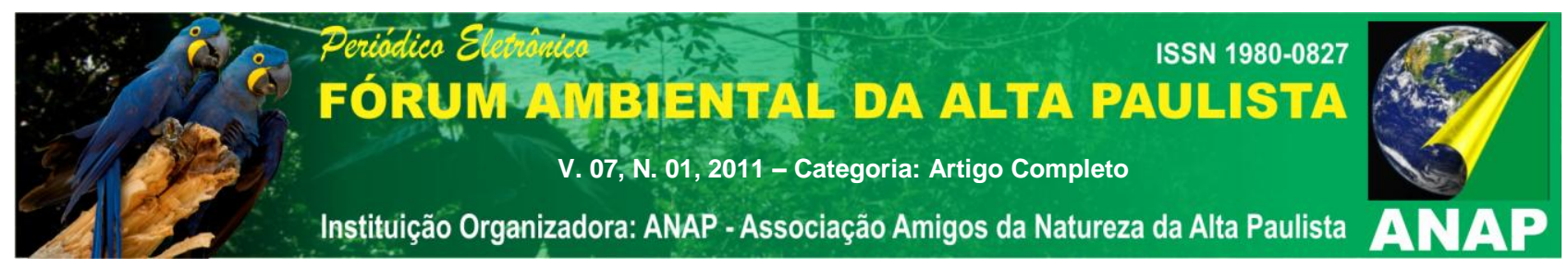

Concentração em Energia na Agricultura - Faculdade de Ciências Agronômicas da UNESP - Campus de Botucatu, Botucatu - SP, 2008.

GOLDEMBERG, José; LUCON, Osvaldo. Energia e meio ambiente no Brasil. Disponível em: <http://www.scielo.br/scielo.php?pid=S010340142007000100003\&script=sci_arttext\&tlng=em>. Acesso em: 18 out. 2010.

JANÉ, Dario. Uma introdução a lógica fuzzy. Disponível em: < http://www.faeso.edu.br/horus/artigos\%20anteriores/2004/artigo_dario.pdf>. Acesso em: 19 out. 2010.

LIMA, Áureo; et al. Sistema decisório fuzzy para analise da demanda de energia elétrica. Disponível em: <http://www.camacho.prof.ufu.br/CBA344.pdf>. Acesso em: 17 set. 2010.

VIEIRA, Sonia. Introdução. Elementos de Estatística. São Paulo: Atlas, 2003. p. 11-13. 